\title{
ФРАЗЕОМАТИЗМЫ С КОМПОНЕНТОМ ДРУГ, ДРУЖБА В ЯЗЫКОВОМ СОЗНАНИИ КИТАЙСКИХ И РУССКИХ СТУДЕНТОВ НА ТРАНСГРАНИЧНОЙ ТЕРРИТОРИИ. РЕЗУЛЬТАТЫ АССОЦИАТИВНОГО ЭКСПЕРИМЕНТА
}

\section{PHRASEOMATISMS WITH THE COMPONENT FRIEND, FRIENDSHIP \\ IN THE LINGUISTIC CONSCIOUSNESS OF CHINESE AND RUSSIAN STUDENTS IN THE CROSS-BORDER AREA. THE RESULTS OF THE ASSOCIATIVE EXPERIMENT}

Yan Yuzhuang

O. Ladisova

Summary: Federal State Budgetary Educational Institution of Higher Education "Blagoveshchensk State Pedagogical University" is located on the territory of the cross-border area - which unites two border cities of Russia and China: the city of Blagoveshchensk and the urban district of Kho e Yeh. In this territory, cultural ties are becoming closer, and the history of friendly relations is more clearly manifested in the existing conscious picture of the world of its inhabitants.

The existing programs of linguistic education for Chinese students at the Blagoveshchensk State Pedagogical University are aimed at the formation and improvement of the ontological base. Students who master Russian as a foreign language develop an awareness of not only the linguistic, but also the cultural components of the country of the language being studied. The image of Russia, interest in it, stimulates students to a dialogue of cultures through language, therefore, the formation of a linguistic educational environment is the main task of organizing the space of intercultural communication, which is provided to the university audience. The dialogue between Russian and Chinese cultures is provided by all components of the educational process, including the technologies of additional linguistic and cultural education. Carrying out activities in the environment of the target language involves expanding the communicative and cognitive base of those competencies, the development of which is aimed at the educational process of the university. The cognitions of language and culture are closely related. Immersion in the Russian language environment makes it possible to single out special segments of intercultural communication linguacultural as conceptual and semantic units of communication [10]. Friendship is one of the most important values in public relations. At different times and epochs, friendship has always been of great importance among different peoples of the world. It reflects the national culture, the specifics of the people. Therefore, a lot of scientific linguistic and cultural studies are devoted to the study of the concept of "friendship".

This article analyzes the concepts of "friend", "friendship" in Russian and Chinese languages in order to identify the similarities and differences

\section{Янь Юйчжуан}

аспирант, ФГБОУ ВО «Благовещенский государственный педагогический университет» 13614582298@mail.ru

Ладисова Ольга Владимировна к.филол.н., дочент, ФГБОУ ВО «Благовещенский государственный педагогический университет»

olga-ladisova@yandex.ru

Аннотация: ФГБОУ ВО «Благовещенский государственный педагогический университет» находится на территории трансграничья - которое объединяет два пограничных города России и Китая: город Благовещенск и городской округ Хэйхе. На этой территории культурные связи становятся более тесными, а история дружественных отношений более четко проявляется в существующей сознаваемой картине мира ее жителей.

Существующие в Благовещенском государственном педагогическом университете программы лингвистического образования китайских студентов направлены на формирование и совершенствование ортологической базы. У студентов, которые осваивают русский как иностранный, формируется осознание не только языковых, но и культурных компонентов страны изучаемого языка. Образ России, интерес к ней, стимулирует студентов к диалогу культур через язык, поэтому формирование языковой образовательной среды - основная задача организации пространства межкультурной коммуникации, которую предоставляют аудитории университета. Диалог русской и китайской культур обеспечивают все компоненты образовательного процесса, включая технологии дополнительного лингвокультурологического образования. Проведение мероприятий в среде изучаемого языка предполагает расширение коммуникативно-когнитивной базы тех компетенций, на развитие которых направлен образовательный процесс вуза. Когниции языка и культуры тесно обусловлены. Погружение в русскую языковую среду позволяет выделять особые сегменты межкультурной коммуникации - лингвокультуремы как концептуально-семантические единицы общения [10].

Дружба - одна из важных ценностей в общественных отношениях. В разные времена и эпохи у разных народов мира дружбе всегда придавалось большое значение. Она отражает национальную культуру, специфику народа. Поэтому изучению концепта «дружба» посвящено достаточно много научных лингвистических и культурологических исследований.

В настоящей статье анализируется концепты «друг», "дружба» в русском и китайском языках с целью выявления сходства и различия в понимании значения дружбы, понимания роли дружбы в жизни студентов обучающихся на территории трансграничного региона русскому языку, как иностранному. Для анализа были выбраны китайские и русские фразеоматизмы с компонентами «друг», «дружба», проведен ассоциативный эксперимент, который позволил раскрыть сущность концептов «друг», «дружба» с позиций фразеологии, выявить содержание концепта в когнитивном сознании носителей русского и китайского языка.

Ключевые слова: трансграничье, лингвистическое образование, культурные компоненты, фразиоматизм, ченьюй 成语, друг, дружба. 
in understanding the meaning of friendship, understanding the role of friendship in the life of students studying Russian as a foreign language in a cross-border region.

For the analysis were selected Chinese and Russian phrases e omatizmy with the components of a "friend», "friendship», held associative experiment, kotory th allow mud to reveal the essence of the concepts of «friend», "friendship» with the phraseology position to reveal the concept content of cognitive consciousness of native Russian and Chinese.

Keywords: cross-border area, linguistic education, cultural components, phrasesiomatism, chenyu 成语, friend, friendship.
$\mathrm{O}$ бзор фразеологических представлений о дружбе, друге позволил сделать опрос информантов, русских и китайских студентов, обучающихся на трансграничной территории.

Респондентам были заданы следующие вопросы:

- Вы когда-нибудь слышали данное выражение?

- Вы когда-нибудь употребляли его?

- В какой ситуации оно может быть применимо?

- Что оно может обозначать?

- Существуют ли в русском/китайском языке сходные выражения по смыслу?

Количественный анализ анкет респондентов прово- дился по следующим критериям: знание и оперирование фразеологическими выражениями о друге, дружбе русской культуры и знание и оперирование фразеологическими выражениями о друге, дружбе китайской культуры; знание аналогов представленных фразеологических единиц о друге, дружбе одной языковой культуры в другой языковой культуре, рассматриваемых в рамках выполняемого исследования, выявление образующих концепт признаков.

Результаты анализа анкет респондентов по критериям: знание и оперирование фразеологическими выражениями о друге, дружбе русской и китайской культуры представим на рисунке 1.

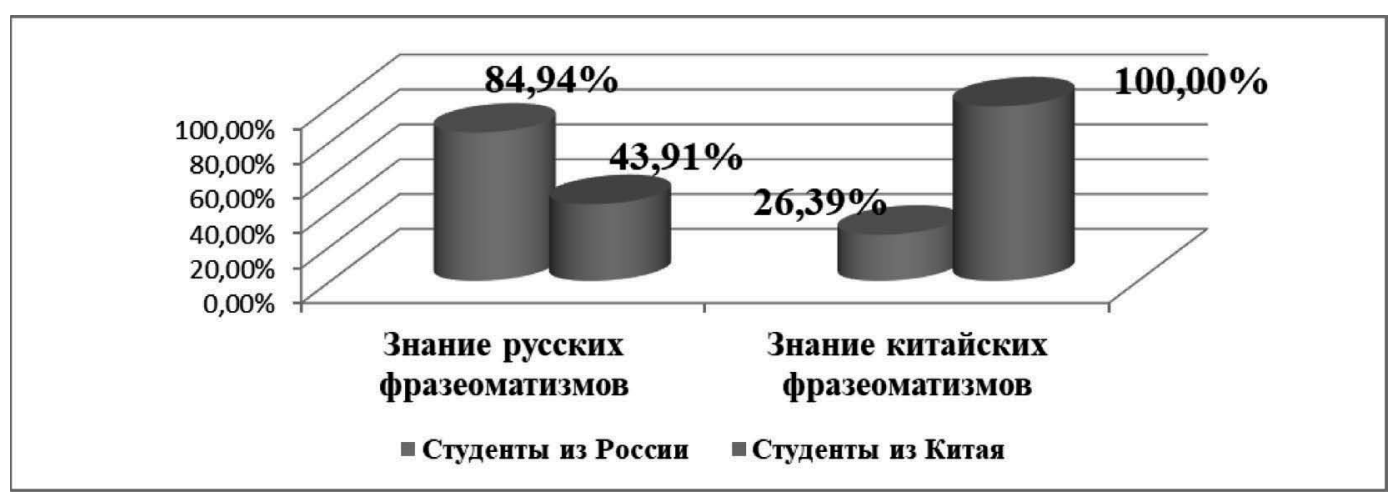

Рис. 1. Результаты анализа

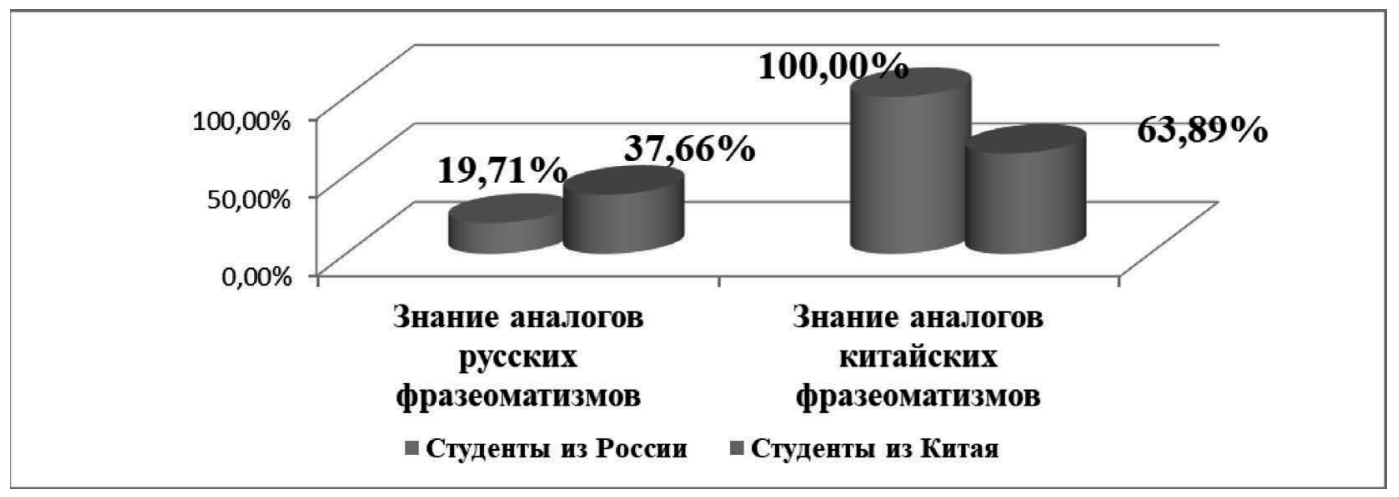

Рис. 2. Результаты анализа 
Полученные данные, представленные на рисунке 1, показывают, что студенты из России значительно лучше знают русские фразеологические единицы о друге, дружбе (84,94\%), чем китайские (43,91\%). Однако, знания студентов фразеоматизмов родного языка, постоянно живущих в России, не составляет 100 \% в отличие от студентов из Китая, которые показали знания китайских фразеоматизмов на уровне $100 \%$. Также важно отметить, что знания фразеоматизмов русского языка студентами из Китая крайне низкие (26,39 \%) и включают в себя знание и оперирование только наиболее распространенными и общепринятыми выражениями, не включающих в себя особенности ранней русской языковой культуры.

Количественный анализ анкет респондентов по критериям: знание аналогов представленных фразеологических высказываний о друге, дружбе одной языковой культуры из другой языковой культуры, рассматриваемых в рамках выполняемого исследования, представлен на рисунке 2 .

Результаты анкетирования, представленные на рисунке 2, показали, что студенты из России смогли подобрать аналоги фразеологических единиц из китайского языка для русских фразеологизмов (19,71\%). Знание аналогов фразеоматизмов в русском языке для китайских фразеологизмов составило 100\%.

Студенты из Китая смогли подобрать аналоги русским фразеологизмам в родном языке в 37,66\% случаев. Знание аналогов фразеологических единиц из русской языковой культуры у носителей китайского языка составило $63,89 \%$.

Качественный анализ анкет респондентов показал, что у студентов из России знания русских фразеоматизмов гораздо более емкие и обширные в сравнении со студентами из Китая, что является закономерным для носителей языка и проживающих в русскоязычной языковой среде. Студенты, проживающие в России постоянно, намного более эрудированы в знаниях русских фразеологических единиц о друге, дружбе. Студенты из Китая знакомы с русскими фразеологическими выражениями о друге, дружбе намного хуже: им знакомы только самые распространенные выражения, а также ощущается недостаточность понимания некоторых из выражений. Указываются неточные значения фразеологических единиц. Например, выражению «старый друг» китайским респондентом дано значение «друг, которому много лет».

Относительно знаний китайских фразеологических высказываний о друге, дружбе можно сказать следующее. Студенты-жители России намного лучше знают предложенные для анкетирования варианты высказываний о дружбе, принятые в китайской культуре. Также российским студентам свойственно владеть нескольки- ми аналогиями высказываний о дружбе из русского языка, что является вполне логичным явлением. Китайские студенты, участвовавшие в анкетировании, оказались хорошо знакомы с собственной культурой и ее лингвистическим аспектом. Однако, подобрать русские аналоги китайским высказываниям, предложенным для анкетирования, студентам из Китая оказалось затруднительно, что количественно представлено на данных диаграммы.

Знание аналогов представленных высказываний о друге, дружбе одной языковой культуры в другой языковой культуре, рассматриваемых в рамках выполняемого исследования представлено следующими особенностями. Фразеологические единицы о друге, дружбе из русской языковой культуры значительно меньше имеют аналогов в китайской культуре. Для многих из них респондентами обеих стран аналоги не были указаны. Китайские высказывания о друге, дружбе нашли в знаниях студентов обеих стран значительно большее количество аналогов русской языковой культуры.

Такие особенности можно объяснить объективными факторами: в исследовании фразеологических единиц из русской языковой культуры было представлено больше, а китайских пословиц и высказываний - значительно меньше, что, соответственно, расширяло диапазон возможностей замены для фразеологизмов китайского языка из русской языковой культуры ввиду широты их смысла. Фразеоматизмы русского языка были представлены в исследовании в значительно большем количестве, что делало их более узконаправленными и ограниченными в трактовке и вызвало затруднения в поиске полного смыслового соответствия в другой языковой культуре.

Исследование показало, что в русской культуре настоящий друг всегда будет рядом с вами, всегда поддержит вас, если вы окажетесь в беде. Подтверждением являются часто указываемые следующие русские фразеологические единицы: «Без беды друга не узнаешь». «Друг познаётся в беде». «Не имей сто рублей, а имей сто друзей». «Человек без друзей, что дерево без корней». Друг очень важен для каждого русского человека. Нельзя измерить дружбу деньгами.

Другая выявленная сторона дружеских отношений в русской культуре - это то, что у друзей обязательно должны быть общие интересы, общее хобби, схожие ценности. Также с позиций русской культуры важно тщательно выбирать друга, так как друг может оказывать на вас сильное влияние, как положительное, так и отрицательное: часто указываемое: «Скажи мне, кто твой друг, и я скажу, кто ты». Кроме того, по мнению русских респондентов, между друзьями должны быть уважительные отношения, поэтому навязывать кому-то свою дружбу, если человек не стремится быть открытым, откровенным и не хочет идти на контакт, не стоит: «Дружба 
не служба - предлагать не нужно». Дружбой дорожи, забывать её не спеши». «Для дружбы нет расстояния». «У друга пить воду слаще мёда».

В китайской культуре дружба также является неотъемлемой частью в жизни и отношениях людей. Для дружбы не важно, богатый ли ты человек или бедный, есть ли у тебя высокие достижения или ты обычный человек. Каждый должен беречь дружбу, каждый должен активно искать близких по духу людей, без друзей китаец чувствует себя одиноким и слабым (по-видимому, это связано с коллективистским мироощущением китайцев, а также с тем, что с позиций демографии китайцев много - они привыкли всегда быть в обществе людей и чувствуют себя некомфортно, если рядом нет друга). Например, указывалось на то, что китайский человек часто говорит, что когда мы молодые, мы всегда ищем новых друзей, а когда старые, то скучаем по старым друзьям（少年乐新 知，哀暮思故友。）- это значит, что старый друг лучше нового друга, потому что он сопровождают нас долгое время, и поэтому он больше понимает нашу жизнь, чем новый друг. В китайской лингвокультуре важно, чтобы друзья держали слово, чтобы дорожили дружбой и не бросали слов на ветер: И на четверке лошадей нельзя догнать неосторожного (君子一言驱马难追. Китайцы считают, что, только соблюдая обещания, можно завоевать доверие своих друзей. Что «Расстояние не может разделить настоящих друзей, они ощущают друг друга не зависимо от расстояния» 相知无远近，万里尚为 邻。）， «Нет в мире большего счастья, чем иметь верных друзей, и еще счастливее - общаться с ними с искренним сердцем» (天下快意之事莫若友，快友之事莫若谈。)

Таким образом, и в русской, и в китайской культурах верный друг, крепкая дружба - это самое ценное, что есть в жизни человека. Понимание данного концепта нашло отражение в приведенных респондентами фразеоматизмах в русском и китайском языках. Для расширения знаний студентов обеих стран необходимо проводить систематическую работу по изучению языковых культур как России, так и Китая на приграничной террритории, что должно обеспечивать высокий уровень лингвистических знаний студентов и языковых навыков. Это не только поможет изучать культуру другой страны, но также построить глубокие дружеские отношения между двумя народами.

\section{ЛИТЕРАТУРА}

1. Большой фразеологический словарь русского языка / ред. доктор филологических наук В.Н. Телия; М.Л. Ковшова, В.В. Красных. - Издательство: АСТПресс, - 2020. 784 с. - ISBN: 5-462-00508-3.

2. Виноградов В.В. 06 основных типах фразеологических единиц в русском языке [Текст] / В.В. Виноградов. Избранные труды. Лексикология и лексикография. - М.,1977. - С. 140.

3. Ма Гофань. Краткий анализ китайской фразеологии / Ма Гофань. - Ляонин: Изд-во Народа, 1958. - 72 с.

4. Мокиенко В.М. Славянская фразеология: Уч. пособие для филол. специальностей ун-тов / В.М. Мокиенко. - М.: Высшая школа, 1980. - 207 с. (5).

5. Молотков, А.И. Фразеологический словарь русского языка / под ред. А.И. Молоткова, Л.И. Войнова, В.П. Жукова [и др.]. - М. Советская Энциклопедия, 1967. -544 C.

6. Молчкова Л.В. Фразеоматизмы как продукт работы фразеоматического кода // Современные проблемы науки и образования / Л.В. Молчкава. - 2014. №4//scince-education.ru.

7. Ожегов С.И., Шведова Н.Ю. Толковый словарь русского языка / Н.Ю. Шведова, С.И. Ожегов. - М., 1999. - 944 с.

8. Пылкова, А.А. Русско-китайское приграничье как пространство межкультурного взаимодействия: монография / A.A. Пылкова //https://fessl.ru/pylkova-aa-russko-kitajskoe-prigraniche-kak-prostranstvo-mezhkulturnogo-vzaimodejstviya-monografiya-a-a-pylkova

9. Розенталь, Д.Р. Большой фразеологический словарь китайского языка / под ред. Д.Р. Розенталь, В.В, Краснянский, Вань Сэн, Шен Яньлин, Лу Шупин [и др.]. - 2015. - 418 с. - ISBN 978-5-94666-772-2.

10. Трансграничье в изменяющемся мире // Журнал. Забайкальский государственный гуманитарно-педагогический университет им. Н. Г. Чернышевского. Чита. 2010. № 1. [Электронный ресурс] http://elibrary.ru/title items.asp?id=31023.

11. Федоров А.И. Фразеологический словарь русского литературного языка / под ред. А.И. Федорова. - Издательство: Lingua, ACT, Acтрель, - 2008. - 880 c.

12. Чжан Шоукан. Фразеологический словарь китайского языка / Чжан Шоукан. - Пекин: 2000. - 606 с. 